\title{
What you need and what you got in Economics higher education: Results from employers' interviews and an alumni survey
}

The Economics Network has conducted a survey of 138 alumni and a serious of interviews with employers of economics graduates in March -April of 2004, to investigate the knowledge and skills acquired in an Economics degree and their relevance to jobs and careers. This is all part of an ongoing research project into learning, teaching and employability in Economics HE.

Graduates' employability is becoming an important factor, which influences the way students are taught at university. Students themselves, while deciding which subject to study, are becoming more and more concerned with their employability prospects. The results of our national student surveys in 2002, 2004 and 2006 show an important shift in the opinions of students on what they consider to be best aspects of the course. In 2002 they named quality of teaching staff, variety of modules in the degree and the intrinsic interest of the subject. In 2004 and 2006 the first two remained, but the third one has changed to the employability prospects of the graduates.

Students praised aspects of the course that makes them better prepared for their future jobs - development of transferable skills, placement years and reputation of the degree in the job market. As one of the students summarises it:

"Today a degree is not enough. In terms of getting a graduate job (a major reason for getting a degree!) additional qualities are required. A course, which provides a range of learning approaches including such useful skills as presentation and project management, are vital for the types of jobs many economics students aim for. The well-balanced course of economics (theory), business management (critical thinking) and placement (work experience) is fantastic in terms of preparing you for the future. It makes four years of university worthwhile."

We have approached employers with questions about the strengths and weaknesses of economics graduates. The strengths they report include economics graduates' analytical way of thinking, their problem-solving abilities and their familiarity with the use and misuse of data. These are some quotes from interviews with the employers:

"What we are looking for in Economics graduates is how well they apply economic theory to real world problems, find the theory and the evidence to support it and dissect the problem before looking for its solution." - HM Customs and Excise

"Economics graduates have an advantage in content knowledge, but they need to be careful not to concentrate too much on the theory, when applying for jobs. We wouldn't accept someone if they didn't have economics." - Private-sector consultancy firm

“We are looking for Economics graduates' ability to apply economic theory to policy in practical situations. They have to know enough of the theory to be able to extract it. That's what we are looking for in selection, people who are able to apply economics to real-life issues." - GES Economist Group Management Unit 
"In problem-solving we are looking to see if applicants are able to quickly recognize problems, clarify the problem, analyse the problem, come up with different options and solve the problem effectively." - Private-sector consultancy firm

Most employers consider:

- problem-solving to be a very important attribute but one with which they are only moderately satisfied because of graduates’ lack of real-world application;

- that understanding of core principles, technical ability, potential and willingness to learn and continually update knowledge are more important than a stock of knowledge;

- that graduates are not particularly good at applying knowledge or understanding to practical work situations because of (i) inability to improvise, (ii) lack of commercial awareness and (iii) lack of appreciation of the human or cultural context within which they are working.

In their interviews, employers see weaknesses of economics graduates in the development of their communication skills e.g. written, oral empathising; their ability to work effectively in teams/groups, which is partly attributed to the lack of group work in many 'traditional' degrees; applying theory to real-world situations and the lack of understanding of the requirements of employers. Developing these skills through the economics curriculum could be an important step forward.

We recognise that alumni are a valuable resource for assessing the quality of economics programs and for developing suggestions to improve them. They can offer a unique perspective on the preparation of students for their future employment and career and their contribution is essential for the evaluation of teaching and learning.

That was one of the reasons for us to involve alumni in our work and the survey. With the help from the Higher Education Academy we received a draft of an alumni survey, which was developed in Leeds and made some revisions to it. Based on the experience of other Subject Centres and understanding the problems they encountered with the alumni surveys, we aimed to overcome them by targeting alumni through two main routes: through the Careers services at universities and through Association of Graduate Careers Advisory Services (AGCAS) by asking individuals, who already have agreed to their case studies to be used by Economics Network, to agree to a phone interview.

Graduates, who have made the transition from study to work, are in a good position to evaluate how the knowledge and skills developed through their degree course relates to the ones required at the work place. There is substantial research on the use of alumni data to improve academic programmes. Among the papers published in this area are Hartman and Schmidt (1995), who observe that "research in alumni satisfaction is fundamental to improved understanding of the educational process and to providing a quality education"; Yorke and Knight (2003) who conducted interviews with graduates on their perceptions of skills and attributes that are important in the workplace; Delaney, who even calls her papers "Voices of Experience: Renewing Higher Education with Alumni Studies"(2000) and “Alumni Recommendations”(2004). 
Our survey consisted of 31 questions, divided between three sections: About you and your institution (13 questions); About your employment (11 questions) and About your study at University (6 questions).

We used the Bristol Online Surveys (BOS) system for running the survey. One hundred and thirty eight respondents took part. This was an observational study and not a controlled experiment. The respondents do not constitute a random sample of all economics graduates in the UK, but a self-selected group, so their views may not fully reflect the opinions of the entire economics alumni population. At the same time the results of the survey are fully consistent with the results of our Students Survey and Employers interviews, as well as the results of the similar surveys in the USA and Australia.

Among the respondents $74 \%$ were male and $25 \%$ were female, while among economics students in general a third are female and among academic economists one fifth is female.

More then half of the respondents were younger then 30 (52.9\%) and 23.9\% were over 40. Every two out of five of the respondents graduated in the last four years and the rest are nearly equally split between those who graduated in the 1980's and in the 1990’s.

\section{Years of Graduation}

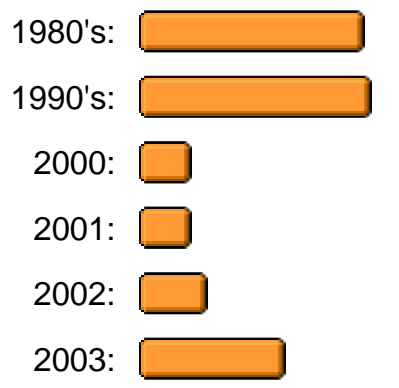

$\begin{array}{cc}29.0 \% & 40 \\ 29.7 \% & 41 \\ 6.5 \% & 9 \\ 7.2 \% & 10 \\ 8.7 \% & 12 \\ 18.8 \% & 26\end{array}$

The respondents, all of which studied for their first degree in economics in the UK come from 10 institutions, with nearly half of them from the University of Southampton.

\section{Universities where Respondents studied for their first degree in economics}

\begin{tabular}{|c|c|}
\hline $\begin{array}{l}\text { University of } \\
\text { Birmingham: }\end{array}$ & $5.6 \%$ \\
\hline University of Bristol: & $4.0 \%$ \\
\hline $\begin{array}{l}\text { University of } \\
\text { Cambridge: }\end{array}$ & $0.8 \%$ \\
\hline University of Dundee: & $12.9 \%$ \\
\hline Heriot-Watt University: & $15.3 \%$ \\
\hline University of Liverpool: & $4.8 \%$ \\
\hline $\begin{array}{l}\text { University of } \\
\text { Manchester: }\end{array}$ & $2.4 \%$ \\
\hline
\end{tabular}


University of Southampton:

The majority of the respondents have studied for single honours degree in Economics (55.0\%), while around a third have joint honors (30.2\%). Nearly all of the respondents studied full-time, with just one graduate studying part-time.

The respondents have received the following degrees:

\section{Degree Classification}

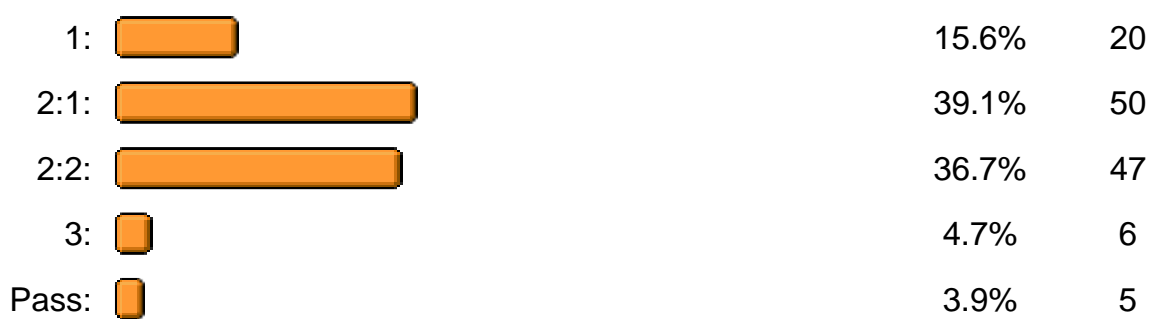

Among the respondents 35.5\% have taken post-graduate qualifications, and 64.5\% have not. English is the first language for $87.5 \%$.

Asked about their employment status, respondents gave the following answers:

\section{Current Employment Status}

\begin{tabular}{rcc} 
full-time employment: & $72.1 \%$ & 98 \\
part-time employment: & $2.2 \%$ & 3 \\
temping: & & 14 \\
$\begin{array}{r}\text { undertaking further } \\
\text { study: }\end{array}$ & $2.9 \%$ & 4 \\
currently unemployed: & $6.6 \%$ & 9 \\
full-time family carer: & $2.2 \%$ & 3 \\
Other (please specify): & $0.0 \%$ & 0 \\
\hline
\end{tabular}

The second section of the survey was dedicated to the employment of the graduates. Only one of the respondents was waiting to start their job. One in ten started their employment in a graduate trainee position, one in nine as an economist, one in five in businesses and accounting, one in sixteen in banking and finance and one in seventeen in teaching and the same number in marketing. The rest of the respondents have started their graduate career with some other job. The diversity of jobs, taken by the respondents reflect the diversity of organisations that employed them: from some big names, like United Nations, the UK Government, Pricewaterhouse Coopers, Bank of Scotland, NatWest, Bank of England to the universities of Duke, Glasgow, Mosul, 
Keele and then to small businesses and schools. When asked what do the organisations, that employed them do, the respondents mention education, banking, finance and civil services, sales and marketing and consultancy.

When asked how qualified they feel to do their job a quarter of respondents felt they were overqualified, while three out of five felt about right. Only one in seventeen felt to be under qualified for their job.

It is interesting to see what the respondents felt were main influences on their decision to take their job. Respondents were asked about nine possible reasons, which may have potentially influenced their decision to take current job. With each reason offered they could agree 'To a great extent', or 'Somewhat' or 'A little / not at all' or 'Not relevant'. The suggested reasons are: Opportunity for professional development; Work which is interesting; Work which is continually challenging; A high degree of work autonomy; Starting salary; The possibility of rapid promotion; Work within clearly defined rules and regulations; The opportunity to be creative and original; $A$ lot of responsibility. Results can be seen from the figure below.

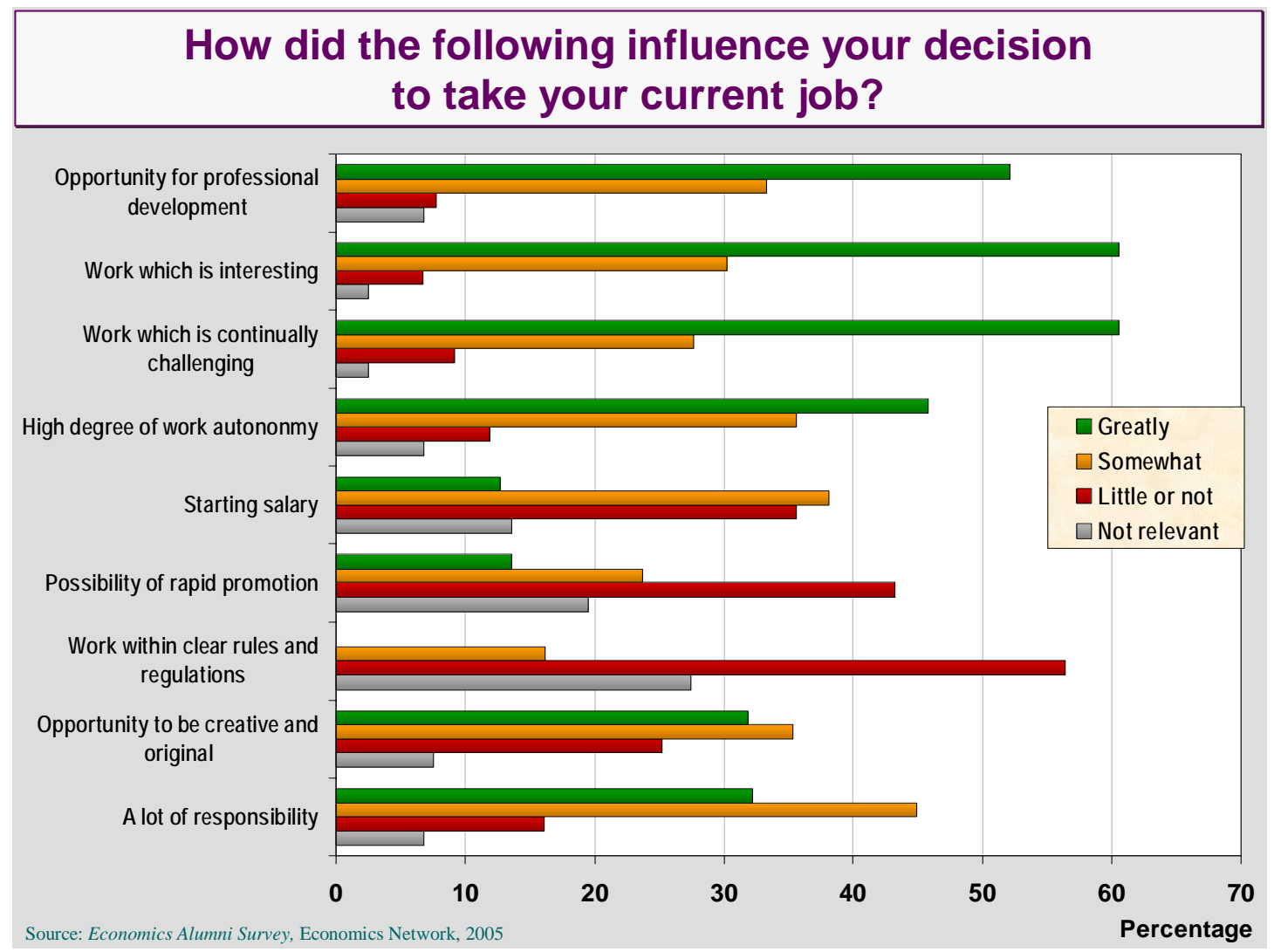

Results suggest that respondents do not value all the reasons equally. More value is placed on 'Work, which is interesting', 'Work which is challenging' and on 'Opportunity for professional development'. Less value is placed on 'Work within clearly defined rules and regulations', 'A possibility of rapid promotion' and 'A starting salary'.

When respondents were asked about their current salaries they have supplied the following information (gross salary per annum in GBP): 


\section{Current salaries of the respondents}

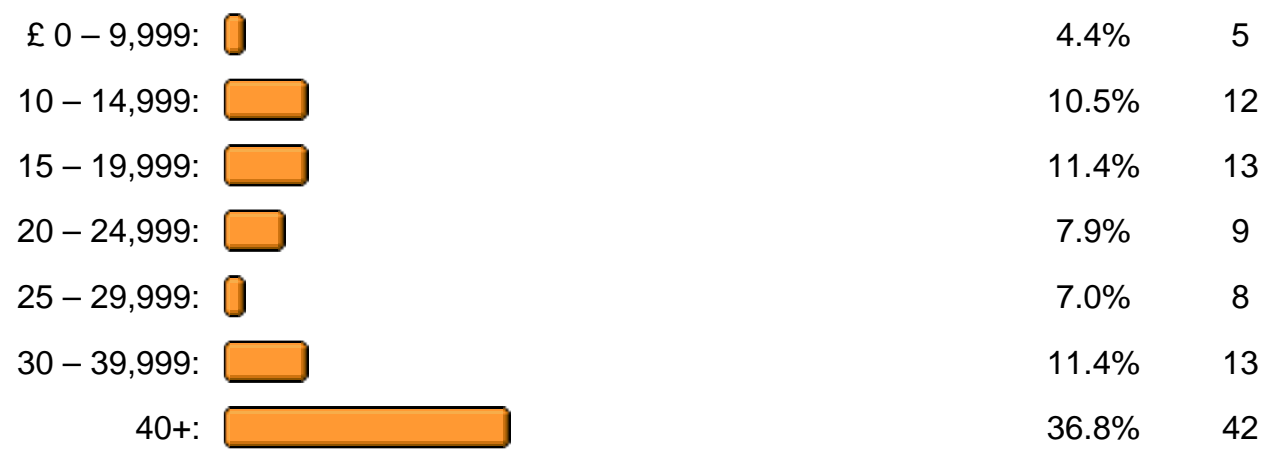

Respondents were asked whether their degree course has given them sufficient opportunity to develop their skills and prepare to the current job in the following areas: Abstraction (the ability to simplify complexity while still retaining relevance); Analysis of economic, business and social issues; the ability to organise, interpret and present quantitative data; Framing (the ability to formulate economic problems, to determine the important parameters and to construct constrained solutions); Understanding and interpreting financial matters; Strategic thinking (conceptualising and identifying the critical issues for economies, businesses and individuals); Communication of economic ideas (the ability to communicate complex concepts to both fellow economists and to lay people).

Their answers can be seen from the following figure below.

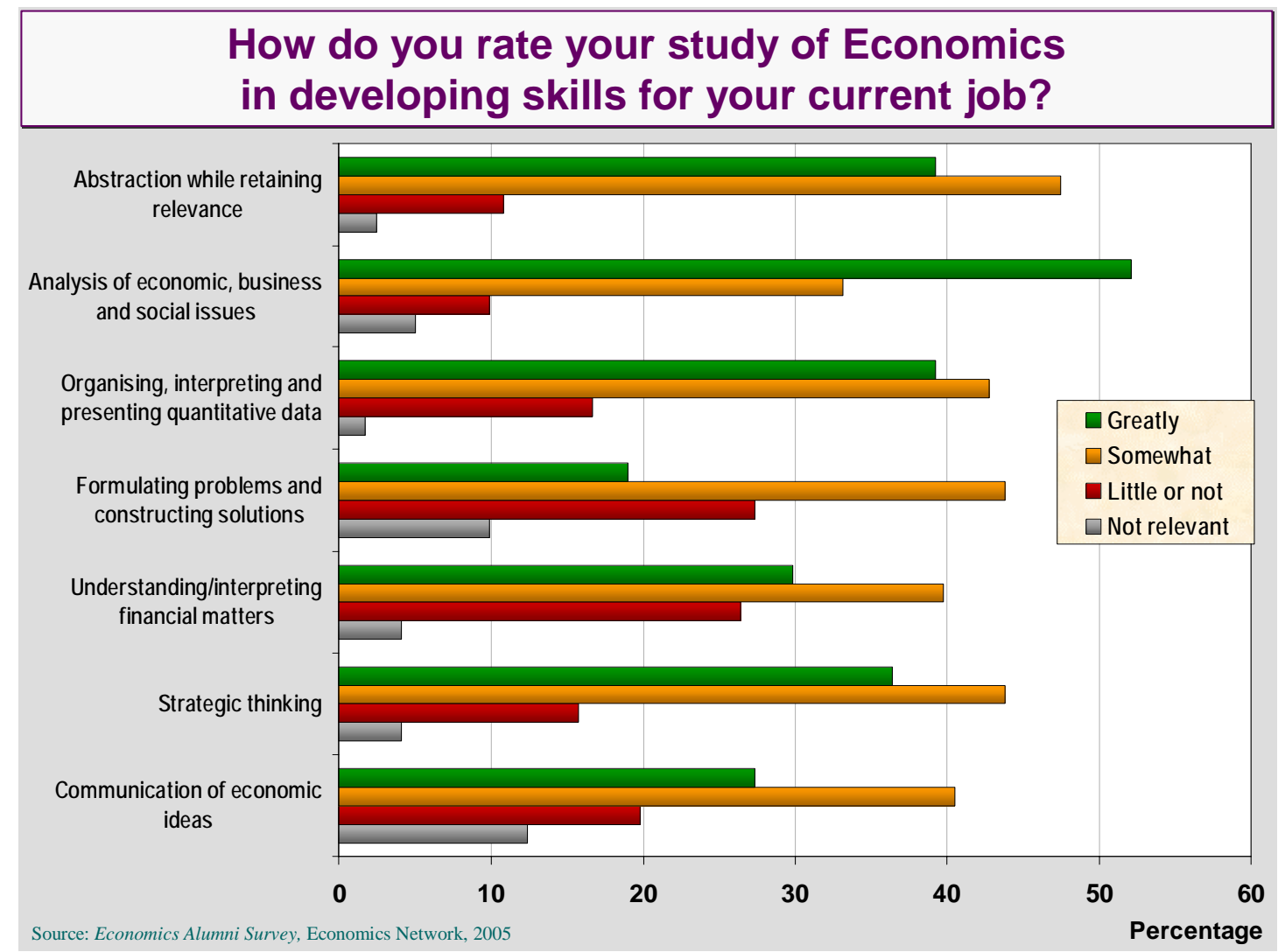


Nearly half of the respondents (48.3\%) agree with the statement that their 'Degree enabled them to get a job they really wanted'. The rest were split between 'My degree enabled me to get a good job, but not the one I really wanted' $-27.1 \%$ and 'My degree has had little or no impact on my job prospects' $-24.6 \%$.

In the third section of the survey the respondents were asked about their study at the university.

They were asked to evaluate how well did their degree course help them to develop generic skills suitable for their current job: the ability to communicate clearly in speech; the ability to communicate clearly in writing; the ability to analyse and interpret quantitative data; a fluency in using IT/computers; the ability to apply what has been learned in a wider context; adaptability (the ability and willingness to plan for and respond to a range of possible situations); general creative and imaginative powers; problem-solving strategies and skills; independence of viewpoint and judgement; awareness of cross-cultural issues; critical self-awareness; ability to work effectively with others; self-reliance (ability to manage your time, your actions and your career without close supervision).

The results of this self-evaluation can be seen in the figure below.

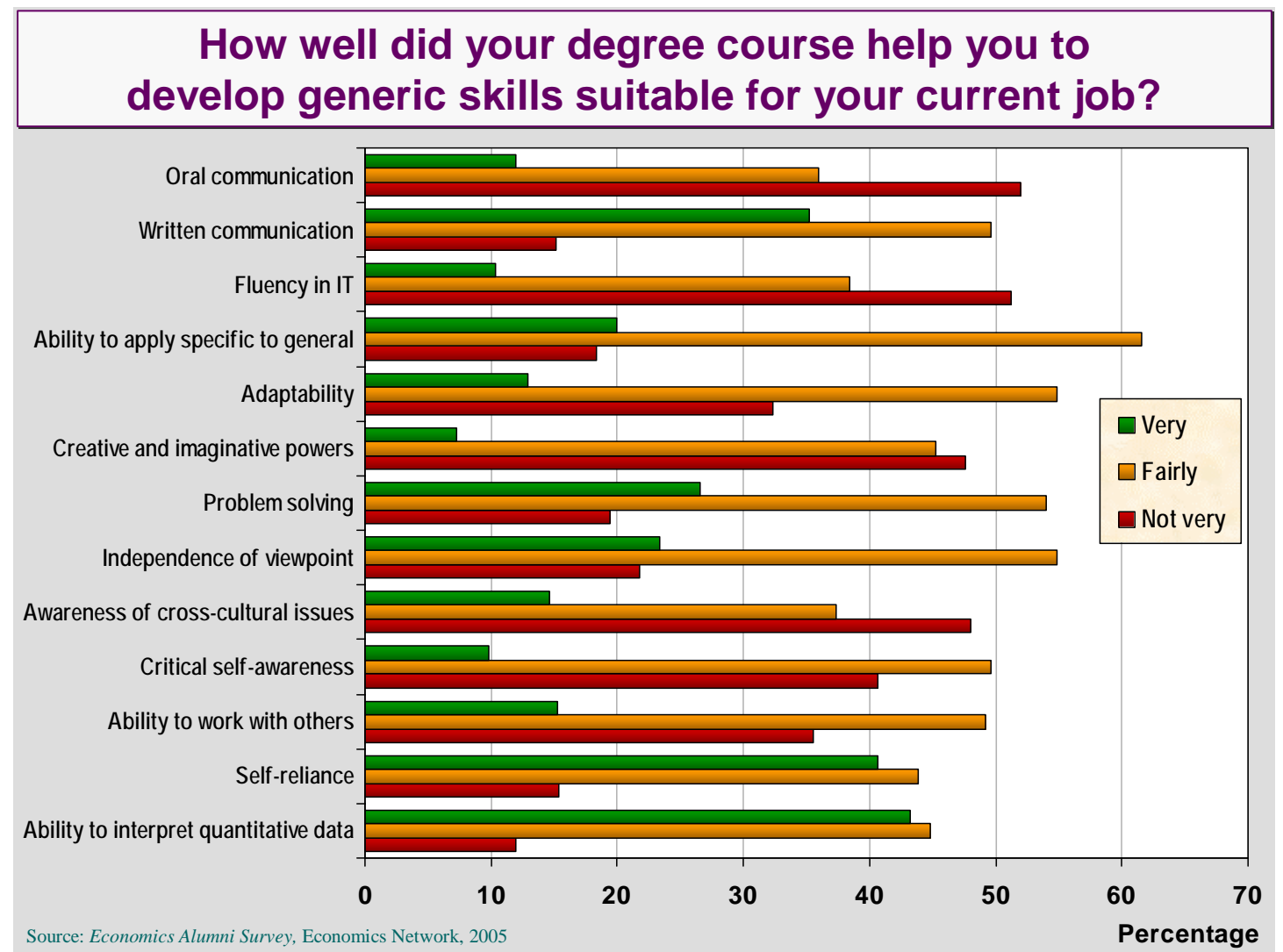

The respondents were also asked to rate their current ability in generic skills: 


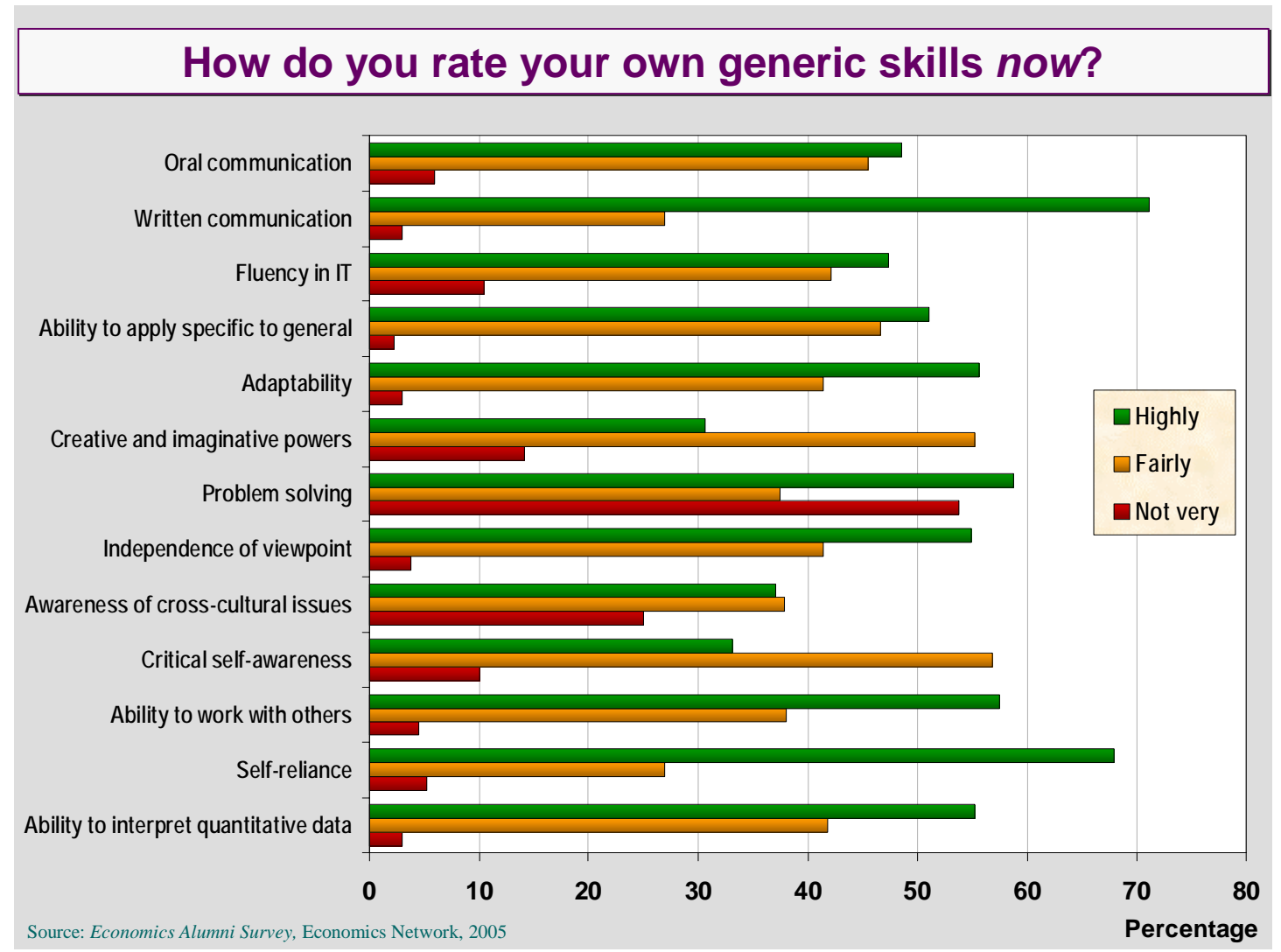

When asked what skills (if any) they gained during their studies that they would like to develop further, the respondents mention communication skills (fluency in speech/ presentations/ public speaking), networking and group working and application of economics to the "non academic world". The skills listed above are similar to the ones mentioned by employers as weaknesses of economics graduates and need to be addressed in the economics curriculum.

When asked what were the least useful aspects of their study respondents often mention courses not directly connected with their current employment. So for some it was - "Econometrics - mainly because I did not use them in my first three years of work and hence lost the ability to conduct the analysis;" for some - "Economics history", for others - "Given my career choice, public economics has yielded little return." Many graduates mention "Too much theory" and "Lack of practical application;" - aspects of the course also mentioned by employers. Some respondents were not happy with the teaching methods of their department "Lack of communication with people, just sitting in lectures listening to a lecturer is not ideal to inspire confidence." Those who have taken Business Studies complain "Business studies, let's be honest, the world doesn't work that way." At the same time there were respondents that felt that " it was all useful in some way" and "I'm sure I would have given a different answer 20 years ago but, over time, most things that I studied then have contributed to my thinking at one stage or another", while some felt "Degree did not prepare you for the workplace at all."

On the whole while asked to look back on their time as an undergraduate and knowing what they do now about careers and the workplace, more than $80.0 \%$ of respondents stated that they would still choose to study Economics at the degree level. 


\section{Looking back on your time as a student and knowing what you do now about careers and the workplace, would you still choose to study Economics at degree level?}

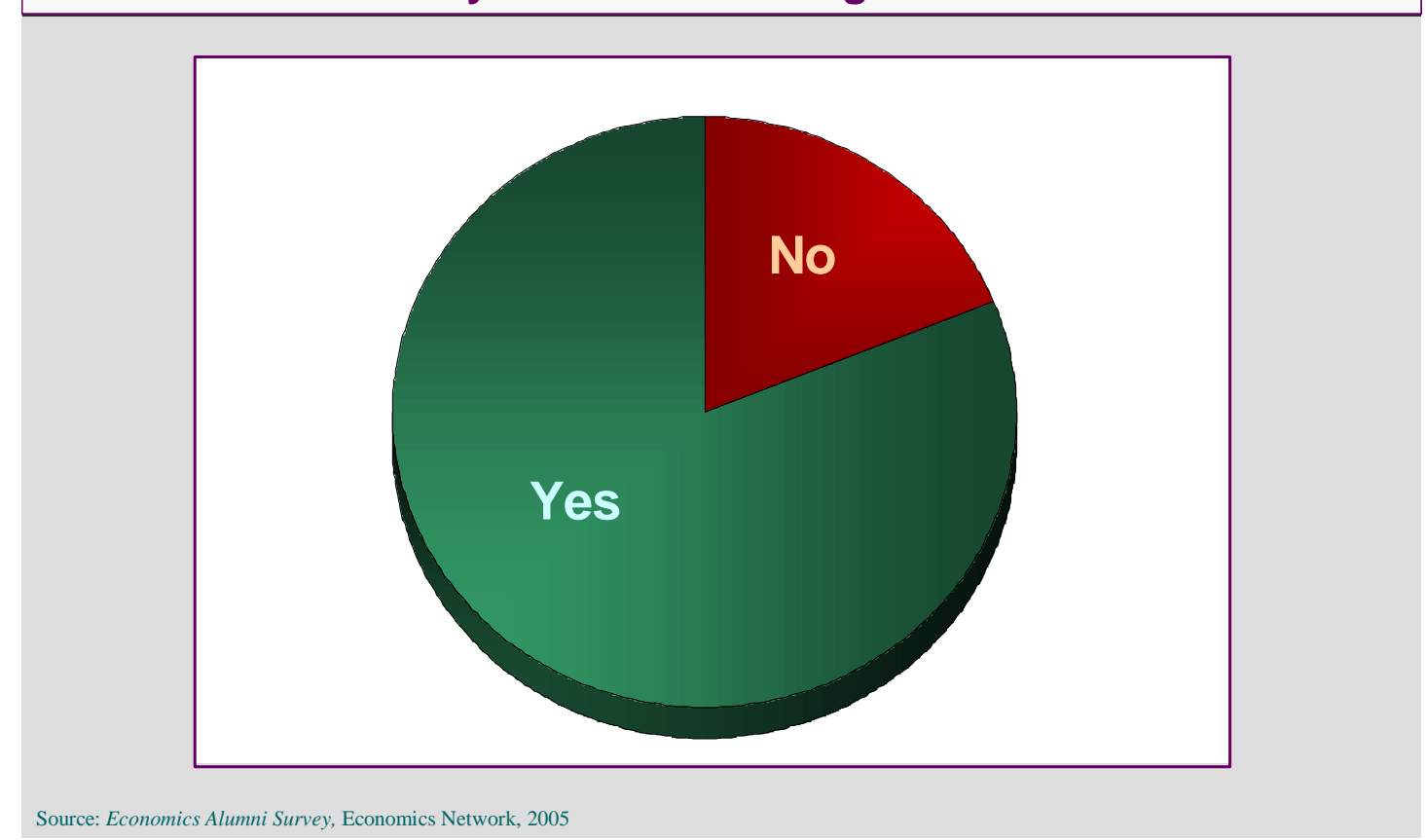

The last question of the survey was about possible comments the respondents would like to make regarding their study time at university. We received both positive and negative comments, some offering suggestions on the further improvement of the course. They range from "It's a waste of time and resources. I've never used my degree in my current job" to "Even though I eventually chose a (relatively) unrelated career I still feel my degree was the best choice I could have made to prepare me for work/life!" Some of the respondents love it - "I loved it. The stimulation, the freedom, the new ideas, the new way of looking at things", others "Had a great time, found lifelong friends, but in reality course content and skills it equipped me with limited," with some even regretting doing a course "I deeply regret going to univeristy at all. If I had gone straight into work then I would a lot better paid and better trained by now. I am now in a situation where I can't find a graduate job and do not have enough experience for a decent non graduate job so I am starting at level as if $i$ did not get a degree. I have advised everyone I know at the decision making age to make sure that if they must go into further education to go to a vocational course."

Suggestions for the improvement of courses included:

- "Definitely not enough preparation for the workplace. Whilst we still need to teach economics, there must be room for IT skills, presentation practice and team work exercises;"

- "The economics part of my course was not as useful as the economic history element. The economics part had very little free thinking, it was more about memorising the text book. I think economic courses need to be more related to the real world and teach you how to apply economic principles to real life work situations more. Looking at a single issue from the viewpoints of different areas of economic specialisms, thinking, training etc would also have 
been useful, as it is often difficult to see the big picture of economics when you are studying as you focus down onto such specific areas;"

- "Fantastic - however, HE institutions that I attended would benefit from exposing undergrads to those using degress in the real world. Academic skill is vital but preparing students to adapt the skills they obtain at Uni to real world situations is critical for the vast majority who do not go on the postgrad work - a useful role for the alumni?"

- "University was great and economics would have been a very useful degree IF we had spent time applying what we had learnt instead of just learning abstract theories. It is no surprise that I am now studying the law."

\section{References}

1. Delaney (2000) Voices of Experience: Renewing Higher Education with Alumni Studies. Tertiary Education and Management 6(2): 137-156

2. Delaney (2004) Ideas to Enhance Higher Education's Impact on Graduates' Lives; Alumni Recommendations. Tertiary Education and Management 10(2): 89-105

3. Employability skills - an employer perspective. Australian Chamber of Commerce and Industry, 2002 http://www.acci.asn.au/text_files/issues_papers/Employ_Educ/ee21.pdf

4. Hartman and Schmidt (1995) Understanding student/alumni satisfaction from a consumer's perspective: The effects of institutional performance and program outcomes. Research in Higher Education 36(2): 197 - 217

5. Yorke and Knight (2003) Employability and Good Learning in Higher Education Teaching in Higher Education, 8(1), pp. 3-16.

6. National Survey of Economics Students (2002) http://www.economicsnetwork.ac.uk/projects/stud_survey2002.htm

7. National Survey of Economics Students (2004) http://www.economicsnetwork.ac.uk/projects/stud_survey2004.htm

8. National Survey of Economics Students (2006) http://www.economicsnetwork.ac.uk/projects/stud_survey2006.htm 